\title{
Sinonasal Inverted Papillomas
}

\section{Sinonazal İnverted Papillomlar}

\author{
Ayca Ant, Samet Özlügedik \\ SBÜ Ankara A.Y. Onkoloji Eğitim ve Araştırma Hastanesi, Kulak Burun ve Boğaz Hastalıkları Kliniği, Ankara
}

Dergiye Ulaşma Tarihi:24.03.2019 Dergiye Kabul Tarihi:05.04.2019 Doi: 10.5505/aot.2019.08379

\section{ÖZET}

GİRIŞ ve AMAÇ: İnverted papillom (İP), sinonazal bölgenin en sık epitelyal tümörüdür. Nükse yatkınlık ve malignite ile ilişkili olması açısından önemlidir. Yassı hücreli karsinom (YHK) odaklarının görülme sıklığı \%515 arasındadır. Genellikle 5-6. dekatta ve erkeklerde 2 kat daha sık görülür. En sık lateral nazal duvardan, ikinci sıklıkta maksiller sinüsten köken alır. En sık tek taraflı burun tıkanıklığı ile bulgu verir. Tedavisi total/geniş cerrahi rezeksiyondur.

YÖNTEM ve GEREÇLER: Sinonazal İP tanısıyla 2007-2017 yılları arasında bir üçüncü basamak sağlık merkezinde cerrahi yapılan hastalar çalışmaya dahil edildi. Hastalar demografik özellikler, belirti ve (klinik ve radyolojik) bulgular, cerrahi, patolojik özellikleri, cerrahi sonrası komplikasyonlar ve uzun dönem takip sonuçları yönünden değerlendirildi.

BULGULAR: Hastaların 12'si erkek (\%86), ortanca yaş 56 (yaş aralığı: 36-79) idi. Patolojik incelemede genel olarak HPV (-) olmakla birlikte, 4 sinonazal İP hastasında YHK, insitu YHK odağı veya takipte YHK gelişimi (\%29) gözlendi.

TARTIŞMA ve SONUÇ: IP, benign bir neoplazi olmasına rağmen malign içerik ve/veya transformasyon açısından önem arz eden bir hastalıktır. Sonuç olarak, bu durum hastaların yakın takibini gerektirir.

Anahtar Kelimeler: Nazal hastalıklar, papillom inverted, paranazal sinüsler crucial for predisposition to the recurrence and malignancy. The incidence of squamous cell carcinoma (SCC) foci is between $5 \%$ and $15 \%$. It is usually seen in 5-6th decade and 2 times more frequent in males. It commonly originates from the lateral nasal wall, and secondly from the maxillary sinus. The most common finding is the unilateral nasal obstruction. The treatment is total/wide surgical resection. METHODS: The patients who underwent surgery with the diagnosis of sinonasal IP between 2007-2017 in a tertiary referral center were included in the study. The patients were evaluated in terms of demographic features, signs and symptoms (clinical and radiological), surgical, pathological features, postoperative complications, and long-term follow-up results.

RESULTS: Twelve of the patients were male (86\%), the median age was 56 years (range: 36-79 years). Pathological examination was generally HPV (-), and 4 patients with sinonasal IP (\%29) had SCC, in-situ SCC focus, or SCC transformation in the follow-up period.

DISCUSSION AND CONCLUSION: Although inverted papilloma is a benign neoplasm, it is an important disease for malignant content and/or transformation. Consequently, the close follow-up is required for these patients.

Keywords: Nasal diseases, papilloma inverted, paranasal sinuses.

GIRIŞ̧ tümör, normal mukozaya bir pedikül ile

İnverted papillom (İP), sinonazal bölgenin en s1k epitelyal tümörüdür ve bu bölge tümörlerinin \%0,5-5'ini oluşturur $(1,2)$. Etiyolojide alerji, sigara, HPV vb. faktörler çalışılmış olmakla birlikte; hiçbiri için kesin kanıt mevcut değildir (3). Nükse yatkınlık ve malignite ile ilişkili olması açısından önemli bir patolojidir.

Klinik olarak enflamatuar polipten daha vasküler bir görüntüsü mevcut olan bu tutunup invazyon göstermeden komşu yapıları iterek sinonazal bölgeyi doldurur. Histopatolojik olarak ise; siklıkla skuamöz özellikteki çok katlı yassı epitel ödemli stroma içine girintiler oluşturur (4).

Genellikle 5-6. dekatta ve erkeklerde 2 kat daha sik görülür. En sik lateral nazal duvardan, ikinci sıklıkta maksiller sinüsten köken alır. Genelde tek taraflı burun tıkanıklığı ile bulgu verir (5). Yassı hücreli karsinom 
(YHK) odaklarının görülme veya gelişme sıklığı \%5-15 arasındadır (3). Kemikte osteolizis bulgusu malignite varlığı lehinedir (6).

Tedavisi cerrahidir, nüks ve malignite riski göz önüne alınarak total/geniş rezeksiyon yapılır. Açık cerrahi teknikler yerini endoskopik yöntemlere bırakarak morbiditede azalma sağlamıştır. Cerrahi sonrası nüks oranları intranazal kitle eksizyonu yapilan olgularda \%74 iken, endoskopik sinüs cerrahisi ve geniş eksizyon yapılan olgularda \%24'e kadar düşmüştür (7-13).

\section{GEREÇ ve YÖNTEM}

Sinonazal İ tanısıyla, 2007-2017 yılları arasında bir üçüncü basamak sağlık merkezinde cerrahi yapılan hastalar çalışmaya dahil edildi. Hastalar demografik özellikler, belirti ve (klinik ve radyolojik) bulgular, cerrahi, patolojik özellikleri, cerrahi sonrası komplikasyonlar ve uzun dönem takip sonuçları yönünden retrospektif olarak değerlendirildi. Yerel etik kurul onayı alındı (5417/4).

Tedavi planı öncesi, hastaların tam baş boyun muayenesi, nazal endoskopileri yapild1. Sinonazal IP olgular1, paranazal sinüs bilgisayarlı tomografisi (PNBT) ile değerlendirildi, orbita ve/veya intrakranial uzanım veya malignite şüphesi olan olgularda maksillofasiyal manyetik rezonans görüntüleme (MRG) de değerlendirmeye eklendi. Sinonazal IP olguları Krouse Sinıflandırma Sistemi'ne göre radyolojik bulgular ve operasyon notlarına göre evrelendi (Tablo 1) (14). Tümör yaygınlığına göre, hastalara endoskopik sinüs cerrahisi (ESC), Caldwell-Luc girişimi, medial maksillektomi veya total maksillektomi operasyonları yapıldı. Postoperatif takipler endoskopik muayene ve görüntüleme teknikleri ile yapıldı.

\section{SONUÇLAR}

Hastaların 12'si erkek (\%86), 2'si kadındı (\%14). Hastaların ortanca yaşı 56 (yaş aralığı: 36-79) idi. Hastaların en sik şikayeti burun tıkanıklığı idi. 2 hastada ek olarak tek taraflı burun akıntısı şikayeti mevcuttu.

Sinonazal İP olgularının ilk tanıda Krouse Evreleme Sistemi'ne göre dağıllımı şu şekilde idi; $5 \mathrm{~T}_{1}$ (\%36), $6 \mathrm{~T}_{2}$ (\%43), $3 \mathrm{~T}_{3}(\% 21)$. Bir olguda sinonazal IP bilateralken, 6 hastada sağ, 7 hastada sol İP patolojisi mevcuttu ve 2 olguda enflamatuar polip ile birlikte İP izlendi. Patolojik incelemede tüm hastalarda HPV (-) idi. Postoperatif ortalama takip süresi 4 yıldı (2-12 y11). Dört sinonazal İP hastasinda $(\% 28,6) ; 2$ YHK, 1 in-situ YHK odağ 1 ve 1 takipte YHK gelişimi gözlendi.

Sinonazal İP tanisı konan 6 hastaya (\%43) yalnız endoskopik sinüs cerrahisi (ESC), 4 hastaya $(\% 28,6)$ ESC'ye ek olarak medial maksillektomi yapıldı. Üç hastaya $(\% 21,4)$ ESC ve medial maksillektomiye ek olarak Caldwell-Luc girişimi yapıldı. İlk tanıda $\mathrm{T}_{1}$ olup takipte nüks ve sonrasinda YHK gelişen bir hastaya (\%7) total maksillektomi yapıldı. Posroperatif dönemde komplikasyon izlenmedi. Takip süresince hastaların 1'inde (\%7) nüks gözlendi. Bu hasta daha önce radyoterapi (RT) tedavisi almış andiferansiye nazofarenks kanseri (NFK) idi. Sol nazal kavitede $\mathrm{T}_{1}$ evre olarak başlayan bu olgunun takibinde 1 y1l sonra YHK gelişti, 4 defa revizyon cerrahi yapılan hastaya daha önce NFK nedeniyle RT alması nedeniyle ek doz uygulanamadi, kemoterapi verildi. Takiplerinde 1 y1l sonra karaciğer metastazı da gelişen hasta, genel durum bozukluğu sonras1 hastalığı nedeniyle eks oldu.

Tablo 1: Sinonazal İnverted Papillomada Krouse Evreleme Sistemi

\begin{tabular}{|cl|}
\hline $\mathrm{T}_{1}$ & $\begin{array}{l}\text { Tümör nazal kavitede sınırlı, sinüslere } \\
\text { uzanım yoktur. }\end{array}$ \\
\hline $\mathrm{T}_{2}$ & $\begin{array}{l}\text { Tümör ostiomeatal kompleks, etmoid sinüs } \\
\text { ve maksiller sinüs medial duvarı ile sınırlı, } \\
\text { nazal kavite tutulumu olabilir. }\end{array}$ \\
$\mathrm{T}_{3}$ & $\begin{array}{l}\text { Tümör maksiller sinüs lateral, süperior, } \\
\text { inferior, anterior ve posterior duvarında } \\
\text { olmakla birlikte sfenoid sinüs veya frontal } \\
\text { sinüslerden birinde tutulum mevcuttur. }\end{array}$ \\
\hline $\mathrm{T}_{4}$ & $\begin{array}{l}\text { Tümör nazal kavite ve sinüslerin dışına } \\
\text { çımıştır. Orbita, intrakraniyal veya } \\
\text { pterigomaksiller bölge tutulumu görülebilir. }\end{array}$ \\
\hline
\end{tabular}

\section{TARTIŞMA}

IP, histopatolojik olarak çok katlı epitelin stromaya doğru invajinasyonu ile karakterizedir. İnvazyon göstermeyen bu patoloji, benign özellikte olmasına rağmen kitle etkisi ile komşu yapıları destrükte eder, sinonazal İP nüks ve malignite gelişimi açısından önem arz eder (15).

Sinonazal İP, erkeklerde 2-5 kat ve 5060 yaş arası daha sık görülür. Burun tıkanıklığı 
en s1k semptomdur $(5,16)$. Bizim serimizde erkek-kadın oranı daha yüksek, 6 (n:12/2) idi. Kaya ve ark. da benzer şekilde bu oranı 6.3 olarak raporlamışlardır (17). Yaş grubu ve en s1k semptom ise literatürle uyumludur $(5,16-$ 19).

Garavello ve ark. yaptıkları çalışmada rekürren nazal polipli olguların $\% 0,26$ 'sında İP geliştiğini raporlamıştır (20). Bu çalışmada ise, 2 olguda (\%14) histopatolojik olarak İP nazal polip ile birlikte izlenmiştir. Bu nedenle nazal polip olarak düşünülen cerrahi materyallerin de histopatolojik değerlendirilmesi önemlidir.

\begin{abstract}
Sinonazal İP olgularının preoperatif değerlendirme ve takiplerinde PNBT önemlidir. PNBT, olguların evrelenmesi ve cerrahi genişliğini belirlemede yardımcıdır. Buna ek olarak fokal hiperosseöz alanların İP'nin köken aldığı alanlar olması ile bu bölgelerin geniş cerrahisi nüksü azaltması açısından önemlidir (21). MRG ise şüpheli olgularda inflamasyon-kitle ayrımında yardımc1 olmakla beraber orbital ve intrakranial tutulumu değerlendirme açısından önemlidir. Çalışmamızda tüm olgular preoperatif olarak PNBT ile değerlendirilmiş, evreleme ve cerrahi planı bu şekilde yapılmıştır. Maksillofasiyal MRG, YHK içeren ve gelişen 4 hastada takiplerde kullanılmıştır.
\end{abstract}

İP evrelemesinde farklı sistemler kullanılmıştır. En sik kullanılan Krouse Evreleme Sistemi tanı ve tedavide yardımc1 olması dışında, olguların sınıflandırılması ile risk grubunu da ortaya koyar. Literatürde endoskopik ve ileri cerrahi yöntemler ile nüks oranları \%0-24 arasında değişmektedir (13). Cannady ve ark.'nın yaptığı çalışmada nüks oranları $\mathrm{T}_{1}, \mathrm{~T}_{2}, \mathrm{~T}_{3}, \mathrm{~T}_{4}$ evre tümörlerde sirasiyla $\% 0, \% 4, \% 19,2, \% 35,3$ olarak raporlanmıştır (22). Başka bir çalışmada aynı oranlar sırasıyla $\% 4,3, \% 4,2, \% 7,3, \% 100$ olarak raporlanmıştır (23). Keskin ve ark. ise bu oranları \%0, \%7,6, $\% 20$ olarak raporlamıştır (18). Bizim serimizde ise tüm olgular içinde, sadece daha önce NFK nedeniyle KRT tedavisi alıp kür olan ve tanı anında $T_{1}$ evrede olan 1 hastada (\%7) nüks ve takiplerde malignite gelişimi izlendi. Sinonazal İP olgularının maligniteye dönüşme oranı $\% 9,1$ olarak raporlanmıştır (3). Bizim çalışmamızda 4 olguda $(\% 28,5)$ malignite içeriği ve gelişimi izlenmiştir. $\mathrm{Bu}$ olgulardan birinde (\%7) RT hikayesi mevcuttur. Erken evre ile başlayan bu hastanın RT hikayesinin olması nüks ve malignite riski açısından önem arz etmektedir.

Sinonazal İP'de tümörün yaygınlığ cerrahi yaklaşımı belirlemektedir. $\mathrm{T}_{1}$ olgularda genelde lateral duvardan kaynaklanan nazal kavitedeki kitle pedikülün tutunduğu normal mukoza ile beraber çıkarılır. $T_{2}$ olgularda maksillanın medial duvarına tutunan kitlenin ESC ile eksizyonu dışında sıklıkla medial makillektomi de gerekir. ESC ile ulaşımı güç olan $\mathrm{T}_{3}$ olgularda Caldwell-Luc girişimi, eksternal yaklaşım ile maksillektomi ve ileri $\mathrm{T}_{4}$ olgularda ise orbital veya kraniyal cerrahiler gerekir (5). Bizim serimizde, $\mathrm{T}_{4}$ hasta olmamas1 nedeni ile orbital veya kraniyal cerrahi gereği oluşmamıştır. Yalnız ESC ile 4 $\mathrm{T}_{1} \quad(\% 36)$ ve $2 \mathrm{~T}_{2} \quad(\% 14)$ olguda kür sağlanmıştır. Medial maksillektomi ESC'ye ek olarak $4 \mathrm{~T}_{2}(28,6)$ olgusuna; ESC ve medial maksillektomiye ek olarak Caldwell-Luc girişimi $3 \mathrm{~T}_{3}(\% 21,4)$ olgusuna yapılmıştır. $\mathrm{T}_{1}$ olarak başlayıp YHK gelişen 1 olguya total maksillektomi yapılmış fakat kür sağlanamamıştır.

Sonuç olarak; nüksü önlemek için, tümörün kaynaklandığı alanı subperiosteal disseksiyonla normal doku ile birlikte çıkarmak önemlidir. Tüm olgularımızda bu yöntemin kullanılmasının ve uzun dönem yakın takibin, nüks ve malignite oranlarının düşük olmasında etkili olduğunu düşünmekteyiz. Baş boyun RT hikayesi gibi hasta faktörünün önemli olduğu olgularda geniş cerrahi işlemlerden kaçınılmaması gereklidir.

\section{REFERANSLAR}

1. Lund VJ. Granulomatous disease and tumors of the nose and paranasal sinuses. In: Kennedy D, Bolger B, Zinreich J, eds. Disease of Sinuses: Diagnosing and Management. London, UK, Decker Inc; 2001:85-106.

2. Batsakis JG. Patology of lesions of the nose and paranasal sinuses; clinical and patologic considerations. In: Goodmann JL, ed. The Principles and Practice of Rhinology,New York, Chichester, Brisbane: John Wiley and Sons; 1987: 45-51.

3. Mortuaire G, Arzul E, Darras JA, Chevalier D. Surgical management of sinonasal inverted papillomas through endoscopic approach. Eur Arch Otorhinolaryngol 2007;264:1419-24.

4. Hyams VJ. Papillomas of the nasal cavitiy and paranasal sinuses. Ann Otol Rhinol Laryngol 1971;80:192-206. 
5. Çomoğlu Ş, Keleş N. Transnazal Endoskopik Benign Tümör Cerrahisi-İnverted Papillom. Turkiye Klinikleri J ENT-Special Topics. 2013;6:119-23.

6. Batsakis JG. The patology of head and neck tumors: nasal cavity and paranasal sinuses, part 5 . Head Neck Surg 1980;2:410-9.

7. Alford TC, Winship T. Epithelial papillomas of the nose and paranasal sinuses. Am J Surg 1963;106:764-7.

8. Norris HJ. Papillary lesions of the nasal cavity and paranasal sinuses. Laryngoscope 1963;73:1-17.

9. Snyder RN,Perzin KH. Papillomatosis of nasal cavity and paranasal sinuses (inverted papilloma, squamous papilloma). A clinicopathologic study. Cancer 1972;30:668-90.

10. Trible WM, Lekagui S. Inverting papilloma of the nose and paranasal sinuses: report of the cases.Laryngoscope 1971;81(5):663-8.

11. Weissler MC, Montgomery WW, Turner PA, Montgomery SK, Joseph MP. Inverted papilloma. Ann Otol Rhinol Laryngol 1986;95:215-21.

12. Lawson W, Le Benger J, Som P, Bernard PJ, Biller HF. Inverted papilloma: an analysis of 87 cases. Laryngoscope 1989;99:1117-24.

13. Gras-Cabrerizo JR, Montserrat-Gili JR, MassegurSolench H, León-Vintró X, De Juan J, Fabra-Llopis JM. Management of sinonasal inverted papillomas and comparison of classification staging systems. Am J Rhinol Allergy 2010;24(1):66-9.

14. Krouse JH. Development of a staging system for inverted papilloma. Laryngoscope 2000; 110(6):965-8.

15. Kazkayası M, Arıkan OK, Dikici O, Tahran FD. Inverted papillomas accompanied by mucocele or carcinoma: case report]. Turkiye Klinikleri J Med Sci 2009;29:267-72.

16. Eweiss A, Al Ansari A, Hassab M. Inverted papilloma involving the frontal sinus: a management plan. Eur Arch Otorhinolaryngol 2009; 266:1895-901.

17. Kaya E, Pınarbaşlı MÖ, Türe N, Çaklı H, Gürbüz MK, Turan Ş. Sinonazal İnverted Papillom Olgularımızda Cerrahi Tedavi Sonuçları. Osmangazi Tıp Dergisi. 2018;40:31-8.

18. Keskin İG, İla $\mathrm{K}$, İșeri $\mathrm{M}$, Aydın Ö, Öztürk M. Sinonazal İnverted Papillom; Tedavi Yöntemleri ve Klinik Sonuçları. Turkiye Klinikleri Journal of Medical Sciences. 2013;33:958-64.

19. Acevedo-Henao CM, Talagas M, Marianowski R, Pradier O. Recurrent inverted papilloma with intracranial and temporal fossa involvement: A case report and review of the literature. Cancer Radiother 2010;14:202-5.

20. Han JK, Smith TL, Loehrl T, Toohill RJ, Smith MM. An evolution in the management of sinonasal inverting papilloma. Laryngoscope 2001;111:1395400.

21. Lee DK, Chung SK, Dhong HJ, Kim HY, Kim HJ, Bok KH. Focal hyperostosis on CT of sinonasal inverted papilloma as a predictor of tumor origin. AJNR Am J Neuroradiol. 2007;28:618-21.

22. Stankiewicz JA, Girgis SJ. Endoscopic surgical treatment of nasal and paranasal sinus inverted papilloma. Otolaryngol Head Neck Surg 1993;109:988-95.

23. Vrabec DP. The inverted papilloma: a 25 year study. Laryngoscope 1994;104:582-605 